\title{
CURRENT TRENDS IN THE MANAGEMENT OF SICKLE CELL DISEASE: AN OVERVIEW.
}

\section{*E. M. Isoa}

*Department of Haematology, University of Benin Teaching Hospital Benin City, Nigeria

\section{Correspondence:}

Dr E. M. Isoa

Department of Haematology

University of Benin Teaching Hospital

Benin City, Nigeria

Email: ehiozei@yahoo.com

\section{INTRODUCTION}

Sickle cell disease is an inherited disorder of hemoglobin that has a worldwide impact on health and longevity. Sickle cell disease, characterized by lifelong hemolytic anemia and a wide variety of painful and debilitating vaso-occlusive events, occurs in 70000 to 80000 Americans of African, Mediterranean, or Middle Eastern extraction ${ }^{1}$.

In the United States, the life expectancy for patients with sickle cell disease is shortened by about 30years ${ }^{2}$, while in Africa, where comprehensive medical care is less available, death in early childhood is usual. In Nigeria the incidence is $1-2 \%$ of the population ${ }^{3}$.

Medical advances in management of sickle cell disease has lead to significant increases in life expectancy of this group of patients. Improved public health, neonatal screening, parental and patient education, advances in red cell transfusion medicine, iron chelation therapy, penicillin prophylaxis for children, pneumococcal immunization, and hydroxyurea therapy have all likely contributed to this effect on longevity ${ }^{4}$.

\section{ETIOPATHOGENESIS}

The term sickle cell disorder refers to states in which the red cell undergoes sickling when it is deoxygenated. The sickle cell diseases are those disorders in which sickling produces prominent clinical manifestations. Included are sickle cell-hemoglobin C disease (hemoglobin SC disease), sickle cell-hemoglobin $D$ disease (hemoglobin SD disease), sickle cell $\beta$ thalassemia, and sickle cell anemia. The latter term is reserved for the homozygous state for the sickle cell gene ${ }^{5}$.

There are few diseases of man whose etiology can be traced to as basic a level as sickle cell disease. Sickle cell anemia is due to the substitution of thymine for adenine in the glutamic acid DNA codon (GAG to GTG), which results, in turn, in substitution at $\beta 6$ of valine for glutamic acid $^{6}$. Deoxygenation of $\mathrm{HbS}$ leads to a conformational change that exposes a hydrophobic patch on the surface of the $\beta$-globin chain. Binding of this site to a complementary hydrophobic site on a $\beta$-subunit of another hemoglobin tetramer triggers the formation of large polymers ${ }^{7}$. This leads to the characteristic sickle or elongated shape of erythrocytes. Repeated or prolonged sickling causes progressive 
damage to the erythrocyte membrane which is of primary importance in the pathophysiology and presentation of SCD. Various factors are associated with sickling of red cells which include deoxygenation, vascular stasis, low temperature, acidosis, infections.

When a cell sickles and unsickles repeatedly, the membrane is affected and the cell becomes irreversibly sickled; it remains so even when the oxygen pressure is increased. These are the sickled forms seen on air-dried films. An irreversibly sickled cell has a high hemoglobin concentration and a high calcium and low potassium content, and it may be ATPdepleted $^{8}$.These cells appear to be derived directly from reticulocytes ${ }^{9}$ but have a short intravascular life span, and the severity of the hemolytic process is directly related to the number of these cells in a patient's circulation ${ }^{10}$.

\section{CLINICAL FEATURES}

The newborn infant is protected by the high level of fetal hemoglobin in the red cells during the first 8 to 10 weeks of life. As the level declines the clinical manifestations of sickle cell disease appear, and the hematologic manifestations of sickle disease are apparent by 10 to 12 weeks of age ${ }^{11}$. Many patients with sickle cell anemia are in reasonably good health much of the time, achieving a steady-state level of fitness. This state of relative wellbeing is periodically interrupted by a crisis that may have a sudden onset and occasionally a fatal outcome. The early recognition and subsequent clinical assessment of sickle crises are greatly facilitated by familiarity with the patient's steady state.

Various types of crises occur, and these may be classified as follows: vasoocclusive (painful) crisis, aplastic crisis, sequestration crisis, and hemolytic crisis. The vasoocclusive crisis is the most common and is the hallmark of the patient with sickle cell disease ${ }^{12}$. The frequency with which such crises occur varies from almost daily to less than once yearly. The vasoocclusive crises result from complex interactions between endothelium, plasma factors, leukocytes, and rigid, sickled red cells leading to the obstruction of blood vessels.

Other features of sickle cell disease are associated with the chronic state of this disease and complications arising thereof. These include: bony abnormalities like avascular necrosis of femoral head, hypostenuria, renal failure, priapism, autosplenectomy, jaundice, acute chest syndrome, stroke, retinopathy, leg ulcers, and infections.

\section{$\begin{array}{lll}\text { CURRENT TRENDS IN } & \text { IN }\end{array}$} MANAGEMENT

\section{Neonatal Screening}

The demonstration in 1986 that prophylactic penicillin markedly reduces the incidence of pneumococcal sepsis ${ }^{13}$ provided a powerful incentive for the widespread implementation of neonatal screening for sickle cell disease (SCD $)^{14}$. Neonatal screening, when linked to timely diagnostic testing, parental education, and comprehensive care, markedly reduces morbidity and mortality from SCD in infancy and early childhood ${ }^{14}$. It is imperative that all infants, including those born at home, be screened and that the initial screening test always be obtained prior to any blood transfusion, regardless of gestational or postnatal age. Hemoglobins $(\mathrm{Hb})$ identified by neonatal screening are generally reported in order of quantity. Because more fetal hemoglobin ( $\mathrm{Hb} F)$ than normal adult hemoglobin $(\mathrm{Hb} A)$ is present at birth, most normal infants 
show $\mathrm{Hb}$ FA. Infants with hemoglobinopathies also show a predominance of $\mathrm{Hb} \mathrm{F}$ at birth. Those with SCD show $\mathrm{Hb} \mathrm{S}$ in absence of $\mathrm{Hb}$ A (FS), $\mathrm{Hb} S$ with another hemoglobin variant (e.g., FSC, FSDPunjab), or a quantity of $\mathrm{Hb} S$ greater then $\mathrm{Hb} A$ (FSA). Hundreds of other $\mathrm{Hb}$ variants may also be identified. Most of these variants are associated with few or no clinical consequences, but some are associated with significant anemia or other problems.

\section{Genetic Counseling}

Sickle cell trait (SCT) is not considered to be a health problem, but individuals who test positive should be informed about the implications for their health and family planning. There are two major circumstances in which adults will learn that they have SCT:

1. Parents of a child with SCT. When a newborn with SCT is identified through screening, at least one of the parents will have SCT.

2. Pregnant women. During prenatal care, women from racial groups with a high prevalence of the sickle cell gene are tested for the gene.

SCT counseling has two components -education and decision-making-but the emphasis differs in the two cases above. For the first group, the focus is on education, that is, to enable individuals to make informed decisions, in their own interest, about future family planning. For the second group, the focus is on education and informed decisions, in their best interest, about the current pregnancy ${ }^{15}$.

\section{Psychosocial management}

Sickle cell disease (SCD) is a complex condition that affects the patient, the family, and the patient's and family's relationship with health care providers and the community. It is imperative that teaching the skills necessary for coping with this illness begin at the time of diagnosis and continue throughout the life of the patient and that providers recognize that including the extended family and the community in the education process will ensure the most positive outcome $^{15}$. Psychosocial issues confronting patients, families, providers, and the community, though multiple and multifactorial, can be addressed and result in positive patient outcomes.

\section{Pain}

Severe pain should be considered a medical emergency that prompts timely and aggressive management until the pain is tolerable. The following recommendations are for treatment in the emergency room, day treatment center, or hospital if the patient is admitted directly ${ }^{15}$.

- Begin hydration. Total fluids should not exceed 1.5 times maintenance (including volume for drug infusions). Initial fluid should be 5 percent dextrose + halfnormal saline $+20 \mathrm{mEq} \mathrm{KCl} / \mathrm{L}$, adjusted for serum chemistry results.

- Assess the patient for the cause of pain and complications.

Analgesics are the foundation for the management of sickle cell pain, and their use should be tailored to the individual patient. Sedatives and anxiolytics alone should not be used to manage pain, because they can mask the behavioral response to pain without providing analgesia. Management of pain associated with SCD consists of the use of nonsteroidal anti-inflammatory drugs (NSAIDs), opioids, and adjuvant medications $^{16,17}$. Management of mildto-moderate pain should include NSAIDs or acetaminophen, unless there is a contraindication; these are nonsedating, so patient activities can 
continue. If mild-to moderate pain persists, an opioid can be added. Treatment of persistent or moderateto-severe pain relies on repeated assessments and appropriate increases in opioid strength or dose. The type of oral preparation used depends on the characteristics and expected duration of the pain. If the patient's pain typically is of short duration (less than 24 hours), opioids or formulations with a short duration of action are appropriate, with the advantage of quicker onset of action. For patients whose pain requires several days to resolve, a sustained release opioid preparation is more convenient to take and provides a more consistent analgesia ${ }^{15}$. The combination of nonopioid analgesics with opioids can permit lower doses of the latter. If an opioid like codeine is used, pain relief is accompanied by mild sedation that can facilitate rest.

\section{Infection}

Infection is a major complication of sickle cell disease (SCD). Special preventive measures against infection exist in addition to routine immunizations; treatment regimens are based on local formularies and antibiotic sensitivity tests.

The single most common cause of death in children with SCD is Streptococcus pneumoniae sepsis ${ }^{18,19}$. The unusual susceptibility results from two problems: splenic malfunction, and failure to make specific IgG antibodies to polysaccharide antigens. Two prevention strategies are recommended: vaccination and prophylactic penicillin. The single most important clinical study in SCD in the past 20 years was a randomized, placebo-controlled trial that demonstrated that the administration of penicillin twice a day prevents 80 percent of life-threatening episodes of childhood Streptococcus pneumoniae sepsis $^{20}$. There are also immunization schedules for Haemophilus influenza, Neisseiria meningitides, Influenza, and Hepatitis B. Virtually all adults with sickle cell anemia are functionally asplenic, but their immune systems have matured to allow type-specific polysaccharide antibody production. Because they are not as susceptible as children to overwhelming sepsis and the incidence of sepsis is relatively low, there is only anecdotal evidence about preventive strategies. Streptococcus pneumoniae vaccination is recommended for adults with SCD. Some patients keep penicillin on hand for fever, but most are not prescribed penicillin prophylaxis routinely ${ }^{15}$. Most antibiotic treatments are started empirically, before culture results are available. There is need for the use of broad spectrum antibiotics for SCD patients with fever, before culture results are available.

\section{Transient Red Cell Aplasia}

Because the life span of red blood cells is greatly shortened in sickle cell disease (SCD), temporary suppression of erythropoiesis can result in severe anemia. Transient red cell aplasia (TRCA) typically is preceded by or associated with a febrile illness. Between 70 and 100 percent of episodes of TRCA are due to infection by human parvovirus B19, also the cause of erythema infectiosum ("fifth disease") ${ }^{21}$. Aplasia is the result of direct cytotoxicity of the parvovirus to erythroid precursors, although other progenitors may be affected in some conditions No experimental trials have been reported regarding the management of TRCA. Although many patients recover spontaneously, red cell transfusions should be considered for those who become symptomatic ${ }^{15}$. 
Stroke and CNS Disease

Adults presenting with acute ischemic stroke should be evaluated for tissue plasminogen activator (t-PA) treatment. If $\mathrm{t}-\mathrm{PA}$ is not used, aspirin is appropriate. Adults with transient ischemic attack (TIA) or ischemic stroke should be evaluated for the cause of the ischemia and therapy should be guided by these findings. Alternatives include antiplatelet agents and warfarin. Chronic transfusion is an option, as used in pediatric stroke prevention. Several uncontrolled studies have documented a reduction in recurrent cerebral infarction using chronic blood transfusion with the target of reducing $\mathrm{Hb} \mathrm{S}$ to less than 30 percent of total hemoglobin ${ }^{22,23}$. The reduction in recurrent stroke risk is significant, but patients may still have a stroke despite adequate transfusion and low $\mathrm{Hb} \mathrm{S}$ levels. The use of aspirin $50-325 \mathrm{mg} / \mathrm{d}$ for prevention of stroke is also recommeded ${ }^{15}$.

\section{Eye Disease}

Beginning in childhood, all patients with sickle hemoglobinopathies should have yearly dilated examinations by an ophthalmologist with expertise in retinal diseases. Any patient with a sickle hemoglobinopathy who experiences a change in vision should be referred for ophthalmologic consultation immediately. Central retinal artery occlusion, an event which usually results in permanent, devastating loss of vision, is one of the few bona fide ophthalmic emergencies which demands intervention within minutes to hours after the onset of symptoms. Treatment consists of hyper oxygenation combined with rapid reduction of eye pressure utilizing surgical and medical techniques. Vision loss from hemorrhage or retinal detachment also calls for urgent care, but, unlike acute vascular occlusion, can be appropriately addressed within 24 to
48 hours. Any individual with a sickle hemoglobinopathy who sustains ocular or periocular trauma should be examined immediately by an ophthalmologist because of the increased risk of visual loss from elevated eye pressure associated with hemorrhage into the anterior chamber (hyphema) ${ }^{15}$.

\section{Acute Chest Syndrome (ACS)}

ACS is an acute illness characterized by fever and respiratory symptoms, accompanied by a new pulmonary infiltrate on a chest $x$ ray. Because the appearance of radiographic changes may be delayed ${ }^{24}$, the diagnosis may not be recognized immediately. A major risk factor for the development of ACS is the hemoglobin genotype: the highest incidence is seen in $\mathrm{Hb}$ SS genotype (12.8 events/100 personyears) and the lowest in $\mathrm{Hb}-\mathrm{S}+\beta$ thalassemia genotype (3.9 events/100 person years) ${ }^{25}$. ACS is the second most common cause of hospitalization in sickle cell patients and the most common complication of surgery and anesthesia ${ }^{26}$.

Oxygen. Assessment of blood oxygenation requires determination of baseline arterial blood gases (ABG), and estimation of the alveolar arterial (A-a) oxygen gradient and the $\mathrm{PaO} 2 / \mathrm{FiO} 2$ ratio. Oxygen should be administered to moderately hypoxemic patients $(\mathrm{PaO} 2=70-80 \mathrm{~mm} \mathrm{Hg}, \mathrm{O} 2$ saturation $=92-95$ percent) nasally at a rate of 2 liters per min.

Chronically hypoxemic patients in whom the admission $\mathrm{PaO} 2$ is no lower than in their steady state may still benefit from oxygen because they may not tolerate additional hypoxemia due to ACS. Control of chest pain and incentive spirometry can prevent hypoventilation in most patients ${ }^{27}$.

Transfusions. Simple transfusions (or exchange transfusions) decrease the proportion of sickle red cells and are 
indicated for the treatment of $\mathrm{ACS}^{24,28}$. Transfusions will increase the oxygen affinity of blood in sickle cell patients ${ }^{29}$. The main indication for transfusion therapy is poor respiratory function.

Antibiotics. Intravenous broadspectrum antibiotics should be given to febrile or severely ill ACS patients since it is difficult to exclude bacterial pneumonia or super infection of a lung infarct. Other measures. Optimal pain control and incentive spirometry are important to prevent chest splinting and atelectasis. ${ }^{15}$

\section{Biliary Disease}

Biliary sludge is best managed by serial ultrasound examinations at 12to 24-month intervals unless cholestasis occurs; at that point, laparoscopic cholecystectomy is indicted. Elective laparoscopic cholecystectomy has become the procedure of choice for symptomatic cholelithiasis $^{30}$ because of the shortened hospital stay, lower cost, and fewer immediate surgical complications. One approach to asymptomatic or minimally symptomatic cholelithiasis is careful observation until symptoms dictate surgery. Bacteremia, ascending cholangitis, empyema, and other hyper acute biliary complications require surgery on a more urgent basis, consistent with good surgical practice $^{15}$.

\section{Renal disease}

The kidney in patients with sickle cell disease (SCD) exhibits numerous structural and functional abnormalities, changes that are seen along the entire length of the nephron. These abnormalities include hypostenuria, hematuria, acute renal failure, glomerular abnormalities and chronic renal failure. Patients with SCD should therefore be encouraged to drink liberal amounts of liquids in order to compensate for the fluid loss that is brought on by hyposthenuria.

The treatment of hematuria in SCD involves bed rest, maintenance of a high urinary flow documented by monitoring of intake and output, and, if blood loss is significant, iron replacement and/or blood transfusion. Vasopressin and epsilon-amino caproic acid (EACA) have both been used with variable success ${ }^{31,32}$. However, caution must be exercised when using EACA, as this antifibrinolytic agent may predispose to the formation of clots that can obstruct the urinary collecting system. If prolonged and life-threatening bleeding is coming from one kidney, local resection of the bleeding segment is preferred. Unilateral nephrectomy is a last resort, since bleeding may recur from the other kidney. Hematuria that occurs in SCD is not always a consequence of red cell sickling and papillary necrosis. Other, nonsickling causes also should be considered. For example, renal medullary carcinoma in young subjects with SCD and sickle cell trait ( $\mathrm{Hb}$ AS) has been reported ${ }^{33,34}$. Therefore, a thorough evaluation is recommended when hematuria is initially found in individuals with SCD and $\mathrm{Hb}$ AS.

Proteinuria, which can progress to the nephrotic syndrome, is the most common manifestation of glomerular injury in SCD patients. Moreover, as many as 40 percent of SCD-SS patients with nephrotic syndrome may goon to develop end-stage renal disease $(E S R D)^{35}$. Therefore, patients with persistent proteinuria should have a urine collection obtained for the determination of 24-hour protein excretion, and a nephrology consultation should be requested for consideration of other, nonsickling causes of proteinuria and possible renal biopsy. ACE inhibitors ameliorate pathological changes such as perihilar 
focal and segmental glomerulosclerosis. They also decrease urinary protein excretion in patients with early manifestations of sickle cell nephropathy ${ }^{36}$.

Renal insufficiency occurs earlier in SCD-SS patients than it does in SCDSC patients ${ }^{37}$. Factors that appear to predict renal failure in SCD-SS patients include hypertension, proteinuria, increasingly severe anemia, and hematuria ${ }^{38}$. Finally, the risk of renal failure is increased in those SCD-SS patients with the Central African Republic (CAR) s-gene cluster haplotype. As there is no proven treatment for sickle cell nephropathy, every attempt should be made to slow its rate of progression. The amount of proteinuria can be decreased by the administration of ACE inhibitors, and it is conceivable that the progression of sickle cell nephropathy may be slowed by a prolonged course of these drugs. Patients should avoid nonsteroidal anti-inflammatory drugs (NSAIDs), because NSAIDs have been shown to produce significant declines in the rates of glomerular filtration and renal blood flow in patients with $\mathrm{SCD}^{37,38}$.

Effective control of blood pressure has been reported to slow the progression of end stage renal disease (ESRD) in patients with SCD; they should be treated with standard approaches ${ }^{39}$. Because dehydration can precipitate vasoocclusive events, caution should be exercised in the use of diuretic agents in an individual with obligate hyposthenuria. Every effort must be made to avoid additional renal damage due to urinary tract infection. Infection must be recognized and treated vigorously. Follow-up should be maintained longer than for patients without SCD.

Although erythropoietin levels are generally high in steady-state SCD-SS patients, they are not increased to the level that would be expected for the degree of anemia ${ }^{40}$. One explanation for the relatively decreased erythropoietin levels is the right-shifted hemoglobin-oxygen dissociation curve seen in SCD patients ${ }^{41}$. Erythropoietin levels in SCD patients fall still further as renal function worsens and these patients may require substantially higher doses of erythropoietin than are required for patients with other forms of $E_{S R D}{ }^{42}$. If erythropoietin is ineffective, transfusions can be given; they must be done carefully, however, to avoid volume overload. As with all patients who develop ESRD, SCD patients can be treated with both hemodiaylsis and peritoneal dialysis, and they can undergo renal transplantation.

\section{Priapism}

Beginning in early boyhood, males need to know that priapism is one aspect of SCD and that this is not an event that should embarrass them. Boys and young men, as well as their families, need to know that they should be prepared to seek medical attention as soon as an episode begins and that if untreated, priapism can result in impotence in the future. The males should know that a full bladder can trigger priapism, and they therefore need to urinate regularly. They also should avoid prolonged sexual activity, which can trigger an episode. If they have had more than one episode, medications can be prescribed that may prevent recurrences. The goal of therapy is to ease pain, make the erection go away, and preserve future erectile function. If treatment is given within 4 to 6 hours, the erection can generally be reduced with medication and conservative therapy ${ }^{15}$. Patients should be advised to drink extra fluids, use oral analgesics, and attempt to urinate as soon as priapism begins. 
For episodes lasting more than two hours, patients should go to the emergency room to receive intravenous hydration and parenteral analgesia. According to one protocol ${ }^{43}$, if detumescence does not occur in 1 hour after the patient has arrived in the emergency room, penile aspiration is initiated (procedure should be performed within 4 to 6 hours from onset of priapism). The patient receives conscious sedation and local anesthesia; blood is then aspirated from the corpus cavernosum with a 23gauge needle followed by irrigation of the corpora with a $1: 1,000,000$ solution of epinephrine in saline. The concomitant use of automated red cell exchange transfusions to reduce the sickle hemoglobin ( $\mathrm{Hb} \mathrm{S}$ ) level to less than 30 percent can also be considered, especially if early intervention with irrigation fails ${ }^{44}$. If there is recurrence despite aspiration and local instillation of vaso-active drugs, shunting may be considered. In this procedure, known as the Winter procedure, a shunt is created between the glans penis and the distal corpora cavernosa with a Tru-cut biopsy needle; this allows blood from the distended corpora cavernosa to drain into the uninvolved corpus spongiosa ${ }^{45}$.Additional medications used for reversal of priapism include -agonists. If impotence persists for 12 months, the patient may wish to consider implantation of a semi rigid penile prosthesis ${ }^{46}$.

Some physicians prescribe $30 \mathrm{mg}$ of oral pseudoephedrine at night as an attempt to prevent further episodes in those who have had priapism and have required aspiration and irrigation $^{43}$.Injections of leuprolide, a gonadotropin releasing hormone analogue that suppresses the hypothalamic-testicular axis and the production of testosterone, also has also been used with some degree of success as prophylaxis against further episodes $^{47}$. A small (11 patients) double-blind, placebo-controlled crossover study found that oral stilbestrol in doses of $5 \mathrm{mg}$ daily for 3 to 4 days could abort episodes of priapism and that much smaller doses could prevent recurrence ${ }^{48}$. Although hydroxyurea may potentially be of benefit ${ }^{49}$, clinical studies to determine its efficacy in preventing priapism have not been performed.

\section{Musculoskeletal Abnormalities}

Musculoskeletal manifestations of sickle cell disease (SCD) are common and may lead to severe morbidity. Bone and joint involvement result from three main causes: 1) bone marrow hyperplasia, which causes distortion and growth disturbance, particularly in the skull, vertebrae, and long bones; 2) vaso-occlusive events that lead to infarction of metaphyseal and diaphyseal bone and to osteonecrosis of juxta-articular bone; and 3) hematogenous bacterial infection that results in osteomyelitis and septic arthritis. Conservative management by analgesia, rehydration, transfusions and appropriate antibiotics are recommended for uncomplicated cases. Surgical intervention for those with advanced disease and for whom all other conservative measures have failed is recommended $^{15}$. These include, core decompression and osteotomy for osteonecrosis, hip replacement, prosthesis and surgical drainage for septic arthritis and osteomyelitis $^{15}$.

\section{Leg Ulcers}

Between 10 and 20 percent of patients with sickle cell disease (SCD) due to a homozygous hemoglobin $\mathrm{S}\left(\begin{array}{ll}\mathrm{Hb} & \mathrm{S}\end{array}\right)$ genotype (SCD-SS) develop painful, disfiguring, and indolent leg ulcers. The ulcers usually appear between ages 10 and 50 years and are seen 
more frequently in males than in females ${ }^{15}$. Studies to prove the efficacy of treatment of leg ulcers are difficult to perform. One reason is that healing depends on blood circulation, and the cumulative time of bed rest and leg elevation is not easily monitored. In addition, the variable extent of wound debridement is difficult to quantify, and a short period of dependency could erase any gains made in the previous period.

Ankle ulcers are painful, and the patient should be given moderately potent analgesics such as oxycodone. Bed rest and elevation of the leg to reduce edema are useful, though not always practical. Wet-to-dry dressings, even if applied only 2 or 3 times a day, can provide gentle debridement; cooperation of patients increases when they are permitted to dampen the dressing slightly before removal, since it is a painful process. Oral zinc sulfate $(200 \mathrm{mg} 3$ times a day) probably does no harm if it does not cause nausea, and may be worth using $^{15}$. The ulcer size should be measured at every clinic visit; seeing the dimensions shrink can provide encouragement to the patient. Some ulcers will not heal. Rigorous studies have not been done to assess the utility of transfusions for treating leg ulcers, but the ulcers seem to correlate with degree of anemia, which suggests transfusions may help. They should be considered for recalcitrant or recurrent skin ulcers if conservative therapy fails. If transfusions are used, they probably should be continued for 3 to 6 months, and a hemoglobin concentration above $10 \mathrm{~g} / \mathrm{dL}$ with $\mathrm{Hb} \mathrm{S}$ levels less than 50 percent can be achieved $^{15}$. More complete bed rest, systemic antibiotics, transfusions, and skin grafts sometimes help. If split thickness or pinch grafts are to be used, preoperative preparation of the ulcer bed is probably quite important.
Quantitative bacterial cultures of biopsies of the bed and margin are advocated by some ${ }^{50}$ but not all $^{51}$ surgeons as a guide to the time for surgery. Intravenous arginine butyrate infusions have been reported to cause rapid healing of ankle ulcers ${ }^{52}$.

\section{Pregnancy}

Prenatal care for women with SCD should be managed by a multidisciplinary team that includes an obstetrician, nutritionist, primary care physician, and hematologist. The team must decide who will be responsible for each aspect of the patient's care. Close monitoring, combined with prompt diagnosis and aggressive treatment of complications during the prenatal and neonatal period by a multidisciplinary team, will contribute to better outcomes ${ }^{15}$. The clinical problems of SCD, such as new onset seizures, hepatopathy, acute anemia, and painful episodes should be evaluated and managed for pregnant women in the same fashion as for women who are not pregnant. Women who have had previous pregnancy losses or who have multiple gestations may benefit from the early use of transfusions to maintain a hemoglobin level above $9 \mathrm{~g} / \mathrm{dL}^{15}$.

\section{Anaesthesia and Surgery}

- Make sure the operating and anesthesia teams are aware of the diagnosis of a sickle cell syndrome and the need for special attention.

- In patients with SCD-SS, and SCD-SC, simple transfusion to a hemoglobin of $10 \mathrm{~g} / \mathrm{dLshould}$ be performed before all but the lowest-risk procedures.

- Patients with SCD, regardless of genotype, should all receive careful attention, with preoperative monitoring of intake and output, hematocrit, 
peripheral perfusion, and oxygenation status.

- Intraoperative monitoring of blood pressure, cardiac rhythm and rate, and oxygenation should be conducted for all surgical procedures.

- Postoperative care should include attention to hydration, oxygen administration with careful monitoring, and respiratory therapy ${ }^{15}$.

\section{Transfusion}

Used correctly, transfusion can prevent organ damage and save the lives of sickle cell disease (SCD) patients. Used unwisely, transfusion therapy can result in serious complications. Once a decision is made to transfuse, the type of red cells to be given is specified and goals are set for the final post transfusion hematocrit and percent sickle hemoglobin ( $\mathrm{Hb} \mathrm{S}$ ) desired.In general, phenotypically matched, sickle negative, leukodepleted packed cells are the blood product of choice, and a post transfusion hematocrit of 36 percent or less is recommended, since a higher value theoretically causes hyper viscosity, which is dangerous to sickle cell patients ${ }^{15}$. Transfusions are used to raise the oxygen carrying capacity of blood and decrease the proportion of sickle red cells. Clinically, they will improve micro vascular perfusion of tissues.

\section{Induction of Fetal Hemoglobin}

Enhanced concentrations of hemoglobin $\mathrm{F}(\mathrm{Hb} F)$ can inhibit sickle hemoglobin $(\mathrm{Hb} \mathrm{S})$ polymerization and red cell sickling and improve the clinical course of sickle cell disease (SCD). In a cooperative study of the natural history of patients with sickle cell anemia in the United States, the frequency of pain episodes correlated inversely with the $\mathrm{Hb} F$ concentration.
Based on these epidemiologic studies and understanding the biophysics of $\mathrm{Hb} S$ polymerization, a search was launched for pharmacologic agents that could reverse the switch from $Y$ - to $\beta$-globin chain synthesis in erythroid precursors. The first "hemoglobin switching" agent was the nucleoside analog 5-azacytidine ${ }^{53}$, which was followed by butyrate derivatives as compounds which increase $\mathrm{Hb} \mathrm{F}$ gene expression. Other drugs, such as hydroxyurea and erythropoietin, alter maturation of erythroid precursors and promote $\mathrm{Hb} \quad \mathrm{F}$ production indirectly ${ }^{15}$.When both hydroxyurea and erythropoietin were given to patients with sickle cell anemia, an increment in $\mathrm{Hb} F$ concentration beyond that seen with hydroxyurea alone occurred ${ }^{54}$

\section{Hemopoietic cell transplantation}

Hematopoietic cell transplantation (HCT) has curative potential for a broad spectrum of genetic disorders, including sickle cell disease (SCD) ${ }^{55}$. The goal is to eliminate the sickle erythrocyte and its cellular progenitors and replace them with donor hematopoietic pluripotent stem cells that give rise to erythrocytes that express no sickle hemoglobin ( $\mathrm{Hb} \mathrm{S}$ ), thereby reducing $\mathrm{Hb} \mathrm{S}$ levels to those associated with the trait condition. The possibility of preventing serious complications from SCD, which can cause extensive morbidity and early death, is balanced by the risk of severe adverse events after transplantation ${ }^{15}$. Children with SCD who experience significant, noninfectious complications caused by vaso-occlusion should be considered for HCT, and if full siblings are available, HLA typing should be performed.

There are other measures which are still in the developmental stage that will be helpful in the management 
of patients with sickle cell disease. These include:

Clotrimazole- which inhibits Gardos channel pathway of sickle hemoglobin ${ }^{56}$.

Nitric oxide- reduces polymerization tendency of sickle hemoglobin ${ }^{57}$.

Flucor ( ReothRx- poloxamer 188) - a new drug under investigation that is said to be useful in reducing the duration of acute pain crises, thereby shortening hospital stay ${ }^{58}$.

Gene therapy- a process whereby the defective gene of the sickle hemoglobin is replaced with normal gene.

\section{CONCLUSION}

Without major breakthroughs in gene therapy or bone marrow transplantation that make these treatments applicable to a large number of patients, drug intervention will remain the major therapeutic option for sickle cell disease. The likelihood is low of finding a "magic bullet" medication that substantially improves sickle cell disease for all or even most patients. Treatment likely will involve the use of different agents alone or in combination to produce optimal results. Combination therapy currently is not an option for sickle cell disease, since only hydroxyurea has been proven to alter the course of the condition. Many, if not most of the

\section{REFERENCES}

1. Steinberg $\mathrm{MH}$. Management of sickle cell disease. N Engl J Med. 1999; 340:1021-1030.

2. Platt $O$, Brambilla DJ, Rosse WF, et al. Mortality in sickle cell disease. N Engl J Med. 1994; 330:1639-1644.

3. Halim NKD, Famodu AA, Wemambu SNC. Textbook of Clinical Haematology and agents currently under investigation likely will fall short of investigators' hopes. If a few survive the rigors of testing and joint the clinical armamentarium, however, we could mix and match drugs for patients with sickle cell disease. Ideally, the treatment regimens would include drugs with differing modes of action. Hydroxyurea, for instance, combined with clotrimazole would team a drug that enhances fetal hemoglobin production (hydroxyurea) with one that reduces erythrocyte dehydration (clotrimazole). For a particular patient, sickle cell symptoms might be improved substantially by neither drug alone. The combination, however, might significantly ameliorate the condition $^{59}$. A major goal of investigation should be development of interventions that can be used in very young patients. Many of the problems experienced by adults and adolescents with sickle cell disease reflect incremental organ damage by bouts of hypoxia. The affected areas may initially be microscopic. With time, these foci of injury coalesce to form regions of macroscopic injury, such as avascular necrosis of the femur. Prevention must be the watchword as we seek to improve the management of patients with sickle cell disease.

Immunology. $2^{\text {nd }}$ Edition. Ambik. 2001; 24

4. Bunn HF. Pathogenesis and treatment of sickle cell disease.N Engl J Med. 1997; 337:762-769.

5. Reid CD, Charache S, Lubin B, Johnson C, Ohene Frem Pong $\mathrm{K}$ : Management and Therapy of Sickle Cell Disease. Bethesda, MD, National Institutes of 
Health, Heart, Lung and Blood Institute, 1995 pp 96-2117.

6. Beutler E, Lichtman MA, Coller BS et al. Williams Hematology. $6^{\text {th }} \quad$ Edition. McGraw-Hill. 2001: 581

7. Hoffbrand A.V., Catovsky D, Tuddenham

E.G.(2005).Postgraduate

Haematology.

Edition.Blackwell.104

8. Eaton JW, Jacob HS, White JG: Membrane abnormalities of irreversibly sickled cells. Semin Hematol 1979; 16:52.

9. Bookchin RM, Ortiz OE, Lew VL: Evidence for a direct reticulocyte origin of dense red cells in sickle cell anemia. J Clin Invest 1991; 87:113.

10. Serjeant GR, Serjeant BE, Milner PF: The irreversibly sickled cell: A determinant of haemolysis in sickle-cell anaemia. $\mathrm{Br} \mathrm{J}$ Haematol 1969; $17: 527$.

11.Powars DR: Natural history of sickle cell disease-the first ten years. Semin Hematol 1975; 12:267.

12. Serjeant GR, Ceulaer CDE, Lethbridge $R$, et al: The painful crisis of homozygous sickle cell disease: Clinical features. $\mathrm{Br} \mathrm{J}$ Haematol 1994; 87:586.

13. Gaston MH, Verter JI, Woods G., et al. Prophylaxis with oral penicillin in children with sickle cell anemia: A randomized trial. N Engl J Med 1986; 314:15939.
14. Consensus Development Panel, National Institutes of Health. Newborn screening for sickle cell disease and other hemoglobinopathies. JAMA 1987; 258:1205-9.

15. NIH Publication No. 02-2117. Revised May28, $20024^{\text {th }}$ ed. National Institutes of Health, National Heart, Lung, and Blood Institute.

16. Jacox A, Carr DB, Payne R, et al. Management of Cancer Pain. Clinical Practice Guideline No. 9. Rockville, MD: Agency for Health Care Policy and Research, Public Health Service, U.S. Department of Health and Human Services, 1994. AHCPR Pub. No. 940592.

17. American Pain Society. Principles of Analgesic Use in the Treatment of Acute Pain and Cancer; 4th edition. Glenview, IL 1999.

18. Leikin SL, Gallagher D, Kinney $\mathrm{TR}$, et al. Mortality in children and adolescents with sickle cell disease. Cooperative Study of Sickle Cell Disease. Pediatrics 1989; 84:500-8.

19. Gill FM, Sleeper LA, Weiner SJ, et al. Clinical events in the first decade in a cohort of infants with sickle cell disease. Cooperative study of sickle cell disease. Blood 1995; 86:77683.

20. Gaston MH, Verter JI, Woods $\mathrm{G}$, et al. Prophylaxis with oral penicillin in children with sickle cell anemia. A randomized trial. 
N Engl J Med 1986; 314:15939.

21. Serjeant GR, Serjeant BE, Thomas PW, et al. Human parvovirus infection in homozygous sickle cell disease. Lancet 1993; 341:1237-40.

22. Russell MO, Goldberg $\mathrm{HI}$, Hodson A, et al. Effect of transfusion therapy on arteriographic abnormalities and on recurrence of stroke in sickle cell disease. Blood 1984; 63:162-9.

23. Pegelow $\mathrm{CH}$, Adams RJ, McKie $\mathrm{V}$, et al. Risk of recurrent stroke in patients with sickle cell disease treated with erythrocyte transfusions. J Pediatr 1995; 126:896-9.

24. Vichinsky EP, Neumayr LD, Earles AN, et al. Causes and outcomes of the acute chest syndrome in sickle cell disease. N Engl J Med 2000; 342:185565.

25. Castro O, Brambilla DJ, Thorington $\mathrm{B}$, et al. The acute chest syndrome in sickle cell disease: Incidence and risk factors. Blood 1994; 84:643-9.

26. Vichinsky EP, Haberkern CM, Neumayr L, et al. A comparison of conservative and aggressive transfusion regimens in the perioperative management of sickle cell disease. $\mathrm{N}$ Engl J Med 1995; 333:206-13.

27. Bellet PS, Kalinyak KA, Shukla $\mathrm{R}$, et al. Incentive spirometry to prevent acute pulmonary complications in sickle cell diseases. N Engl J Med 1995; 333:699-703.

28. Emre U, Miller ST, Gutierrez M, et al. Effect of transfusion in acute chest syndrome of sickle cell disease. J Pediatr 1995; 127:901-4.

29. Uchida K, Rackoff WR, OheneFrempong $\mathrm{K}$, et al. Effect of erythrocyte apheresis on arterial oxygen saturation and hemoglobin oxygen affinity in patients with sickle cell disease. Am J Hematol 1998; 59:5-8.

30. Jawad AJ, Kurban K, El-Bakry $A$, et al. Laparoscopic cholecystectomy for cholelithiasis during infancy and childhood: cost analysis and review of current indications. World J Surg 1998; 22:69-73.

31.John EG, Schade SG, Spigos $D G$, et al. Effectiveness of triglycyl vasopressin in persistent hematuria associated with sickle cell hemoglobin. Arch Intern Med 1980; 140:1589-93.

32. Immergut MA, Stevenson $T$. The use of epsilon aminocaproic acid in the control of hematuria associated with hemoglobinopathies. J Urol 1965; 93:110.

33. Herring JC, Schmetz MA, Digan $A B$, et al. Renal medullary carcinoma: A recently described highly aggressive renal tumor in young black patients. J Urol 1997; 157:2246-7.

34. Coogan CL, McKiel CF Jr, Flanagan $\mathrm{MJ}$, et al. Renal medullary carcinoma in patients 
with SCT. Urology 1998; 51(60):1049-50.

35. Foucan L, Bourhis V, Bangou J, et al. A randomized trial of captopril for microalbuminuria in normotensive adults with sickle cell anemia. Am J Med 1998; 104(4):339-42.

36. Powars DR, Elliott-Mills DD, Chan L, et al. Chronic renal failure in sickle cell disease: risk factors, clinical course, and mortality. Ann Intern Med 1991; 115:614-20.

37. Allon M, Lawson L, Eckman JR, et al. Effects of nonsteroidal anti-inflammatory drugs on renal function in sickle cell anemia. Kidney Int 1988; 34:500-6.

38. De Jong PE, de Jong-van den Berg TW, Sewrajsingh GS, et al. The influence of indomethacin on renal hemodynamics in sickle cell anemia. Clin Sci 1980; 59:24550.

39. Nissenson AR, Port FK. Outcome of end-stage renal disease in patients with rare causes of renal failure. I. Inherited and metabolic disorders. Quart J Med 1989; 271:1055.

40.Sherwood JB, Goldwasser E, Chilcote $\mathrm{R}$, et al. Sickle cell anemia patients have low erythropoietin levels for their degree of anemia. Blood 1986; 67:46-9.

41. Morris J, Dunn D, Beckford M, et al. The haematology of homozygous sickle cell disease after the age $40 . \mathrm{Br} \mathrm{J}$ Haematol $1991 ; 77: 382-5$.

42. Steinberg $\mathrm{MH}$. Erythropoietin for the anemia of renal failure in sickle cell disease. $\mathrm{N}$ Engl $\mathrm{J}$ Med 1991; 324:1369-70.

43. Mantadakis E, Ewalt $\mathrm{DH}$, Cavender JD, et al. Outpatient penile aspiration and epinephrine irrigation for young patients with sickle cell anemia and prolonged priapism. Blood 2000; 95:78-82.

44. Walker EM Jr, Mitchum EN, Rous SN, et al. Automated erythrocytopheresis for relief of priapism in sickle cell hemoglobinopathies. Urol1983; 130:912-6.

45. Winter CC. Priapism cured by creation of fistulas between glans penis and corpora cavernosa. J Urol 1978;119:27

46. Douglas L, Fletcher $H$, Serjeant GR. Penile prostheses in the management of impotence in sickle cell disease. $\mathrm{Br} \mathrm{J}$ Urol 1990; 65:533-5.

47. Levine LA, Guss SP. Gonadotropin-releasing

hormone analogues in the treatment of sickle-cell anemia associated priapism. J Urol 1993; 150:475-7.

48. Serjeant GR, DeCeulaer K, Maude GH. Stilbestrol and stuttering priapism in homozygous sickle-cell disease. Lancet 1985; 2:1274-6.

49. Jam'a AH, Al Dobbous IA. Hydroxyurea in the treatment of sickle cell associated priapism. J Urol 1998;159:1642 
50. Majewski W, Cybulski Z, Napierala M, et al. The value of quantitative bacteriological investigations in the monitoring of treatment of ischaemic ulcerations of lower legs. Int Angiol 1995; 14:381-4.

51. Steer JA, Papini RPG, Wilson APR, et al. Quantitative microbiology in the management of burn patients II. Relationship between bacterial counts obtained by burn wound biopsy culture and surface alginate swab culture, with clinical outcome following burn surgery and change of dressings. Burns 1996; 22:17781.

52. Sher GD, Olivieri NF. Rapid healing of chronic leg ulcers during arginine butyrate therapy in patients with sickle cell disease and thalassemia. Blood 1994; 84:2378-80.

53. DeSimone J, Heller $P$, Hall L, et al. 5-Azacytidine stimulates fetal hemoglobin synthesis in anemia baboons. Proc Natl Acad Sci USA 1982; 79:4428-31.

54. Rodgers GP, Dover GJ, Uyesaka $\mathrm{N}$, et al.Augmentation by erythropoietin of the fetalhemoglobin response to hydroxyurea in sickle cell disease. N Engl J Med 1993; 328:73-80.
55. Parkman R. The application of bone marrow transplantation to the treatment of genetic diseases. Science 1986; 232:1373-8.

56. Brugnara C, Gee B, Armsby C, Kurth S, Sakamoto M, Rifai N, Alper SL Platt O. Therapy with oral clotrimazole induces inhibition of the Gardos channel and reduction of erythrocyte dehydration in patients with sickle cell disease. J. Clin. Invest. 1996; 97: 1227-1234.

57. Head CA, Brugnara C, Martinez-Ruiz R, Kacmarek, et al. Low concentrations of nitric oxide increase oxygen affinity of sickle erythrocytes in vitro and in vivo. J Clin Invest 1997; 100:1193-1198.

58. Adams-Graves P, Kedar A, Koshy $M$, Steinberg $M$, Veith $R$, et al. ReothRx (poloxamer 188) injection for the acute painful episode of sickle cell disease: a pilot study. Blood 1997; 90:2041-2046.

59. Management of sickle cell disease: An overview. Revised Dec. 2000.

http//www.sickle.bwh.havard.ed u. Assessed 10 ${ }^{\text {th }}$ August 2009 